\title{
Hilar cholangiocarcinoma diagnosed by endoscopic ultrasound-guided hepatico- gastrostomy and cholangioscopy
}

A 77-year-old woman, with a history of Whipple resection 20 years previously for a lesion in the porta hepatis that was later determined to be benign, was found to have elevated bilirubin and alkaline phosphatase on routine laboratory testing, prompting a computed tomography (CT) scan of the abdomen ( $\triangleright$ Fig.1). This showed intrahepatic ductal dilatation and pancreatic duct prominence. The patient was referred for gastroenterological investigation with concern for malignancy versus autoimmune cholangiopathy. Single-balloon endoscopic retrograde cholangiopancreatography (ERCP) was

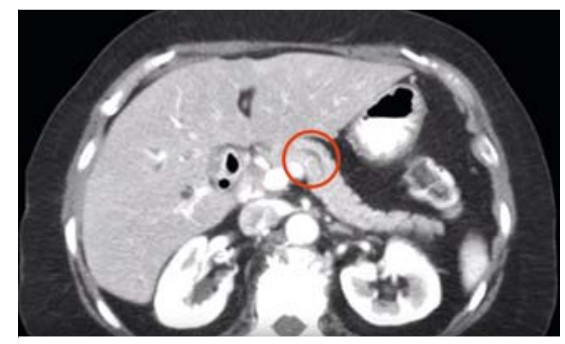

> Fig. 1 Computed tomography (CT) of the abdomen and pelvis shows intrahepatic ductal dilatation and slight prominence of the pancreatic duct, in a 77-year-old woman with a history of Whipple resection 20 years previously.

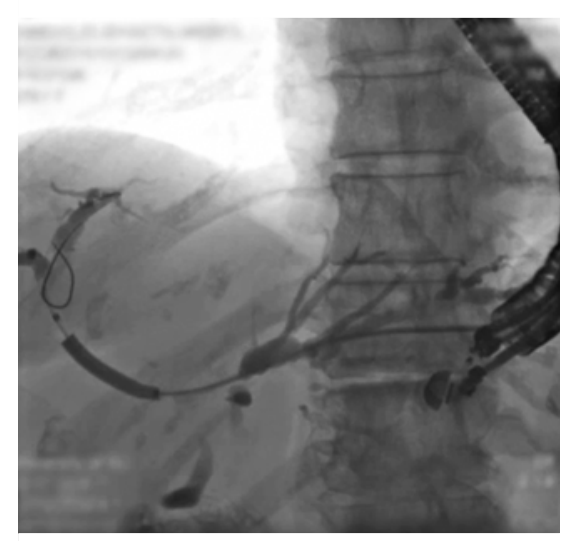

- Fig. 2 A cholangiogram obtained through a hepaticogastrostomy demonstrated stricturing at the hilum and a patent hepaticojejunostomy. attempted but was unable to reach the hepaticojejunostomy. Endoscopic ultrasonography (EUS) was employed to visualize the biliary tree, and demonstrated dilatation of the left intrahepatic bile duct. The duct was punctured under EUS guidance, and a fully covered metal stent was placed from the left hepatic duct into the stomach. A cholangiogram was obtained through the hepaticogas- trostomy, and demonstrated hilar stricturing with a patent hepaticojejunostomy ( $>$ Fig. 2). Both the left and right hepatic ducts were decompressed through the hepaticogastrostomy ( $\mathbf{F i g . 3}$ ).

A second examination was performed with single-operator cholangioscopy through the hepaticogastrostomy (> Fig.4). This demonstrated ulcerated biliary mucosa; brushings were obtained

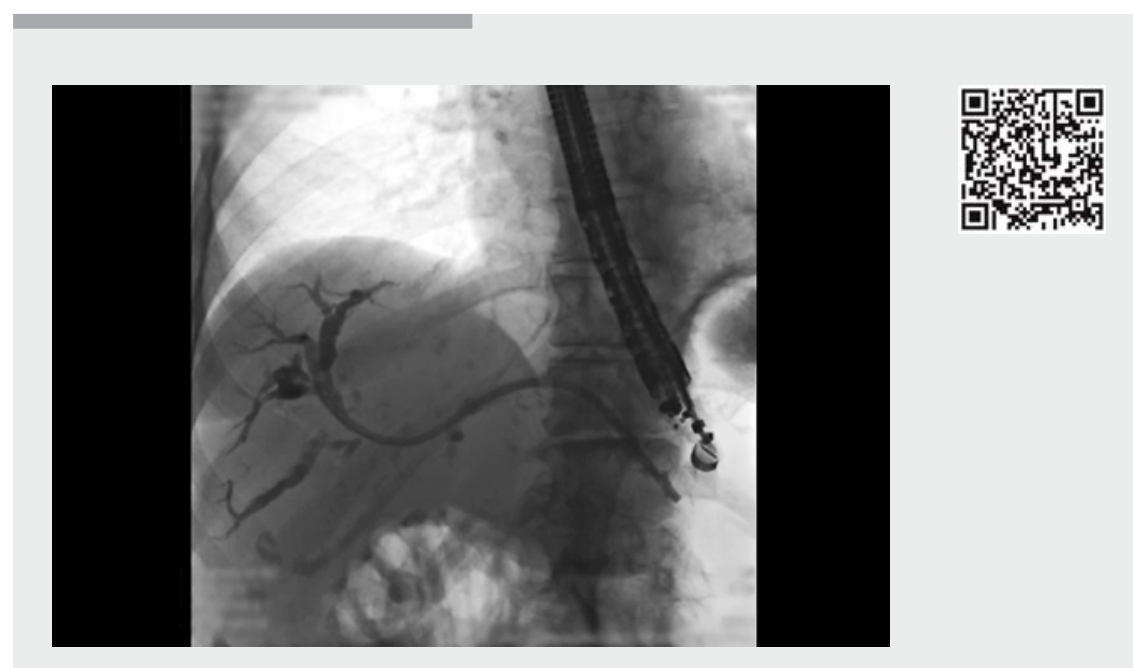

$\checkmark$ Video 1 Hilar cholangiocarcinoma diagnosed by endoscopic ultrasound-guided hepaticogastrostomy (EUS-HGS) and cholangioscopy through the hepaticogastrostomy.

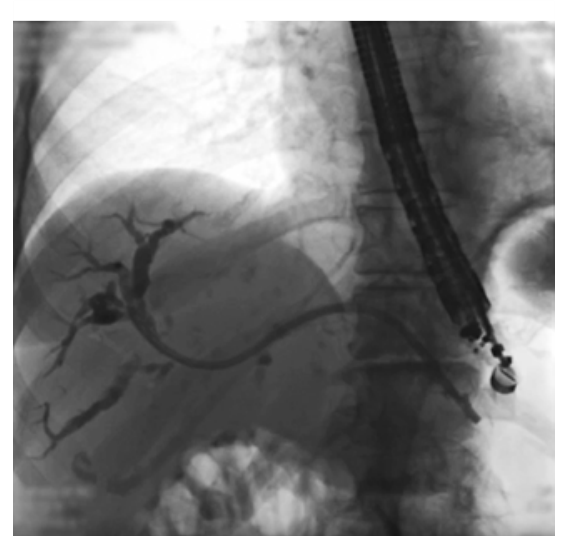

- Fig. 3 A biliary duct stent was placed through the hepaticogastrostomy.

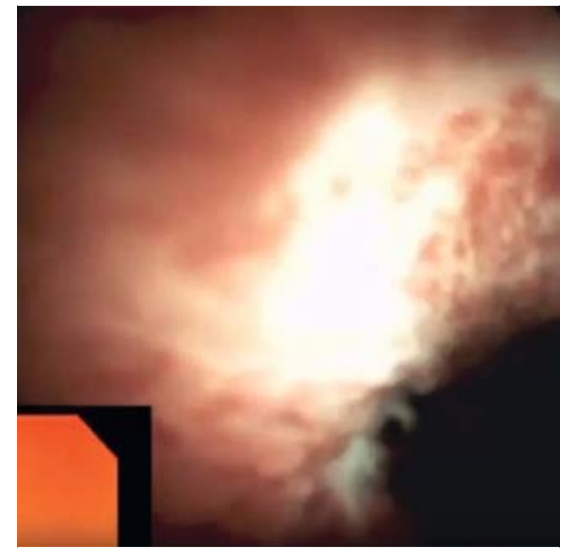

Fig. 4 Cholangioscopy through the hepaticogastrostomy revealed ulcerated, friable, and granular biliary mucosa. 
for cytology and biopsies were taken. A plastic biliary stent was placed within the metal stent to allow continued drainage.

Brush cytology was nondiagnostic; however biopsy tissue from the stricture demonstrated invasive adenocarcinoma. The CA19-9 level at the time of diagnosis was $563 \mathrm{U} / \mathrm{mL}$. The patient was not a candidate for surgical resection, but chemotherapy was initiated. At 4 months after diagnosis, her biliary tree remained adequately decompressed as evidenced by near-normal liver enzyme levels.

A tissue diagnosis is necessary to differentiate hilar cholangiocarcinoma from IgG4 cholangiopathy [1]. This is the first description of hilar cholangiocarcinoma diagnosed via cholangioscopy through an EUS-guided hepaticogastrostomy [2]. The case also serves to demonstrate that both hepatic ducts can be drained through a hepaticogastrostomy into the left duct, which is particularly useful in post-surgical anatomy that limits standard ERCP ( $\triangleright$ Video 1$)$.

Endoscopy_UCTN_Code_TTT_1AS_2AD
T.W. James has no competing interests. I.S. Grimm is a consultant for Boston Scientific. T. H. Baron has received travel and research support from Boston Scientific, ConMed, Cook Medical, Gore Medical, and Olympus, and is a consultant and speaker for Cook Endoscopy.

The Authors

\section{Theodore W. James, Ian S. Grimm, Todd H.} Baron

Division of Gastroenterology and Hepatology, University of North Carolina, Chapel Hill, North Carolina, USA

\section{Corresponding author}

Todd H. Baron, MD

University of North Carolina,

Gastroenterology and Hepatology, 101

Manning Drive, Chapel Hill, NC 27514 ,

United States

Fax: +1-919-843-6899

todd_baron@med.unc.edu
References

[1] Itoi T, Kamisawa T, Igarashi Y et al. The role of peroral video cholangioscopy in patients with IgG4-related sclerosing cholangitis. J Gastroenterol 2013; 48: 504-514

[2] Okuno N, Hara K, Mizuno N et al. Advanced technique for biliary stricture diagnosis using endoscopic ultrasound (EUS)-guided hepaticogastrostomy. Endoscopy 2017; 49 (Suppl. 01): E60-E61

\section{Bibliography}

DOI https://doi.org/10.1055/s-0043-115895

Published online: 31.7.2017

Endoscopy 2017; 49: E260-E261

(c) Georg Thieme Verlag KG

Stuttgart · New York

ISSN 0013-726X

\section{ENDOSCOPY E-VIDEOS}

https://eref.thieme.de/e-videos

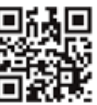

Endoscopy E-Videos is a free access online section, reporting on interesting cases and new

techniques in gastroenterological endoscopy. All papers include a high quality video and all contributions are freely accessible online.

This section has its own submission website at

https://mc.manuscriptcentral.com/e-videos 